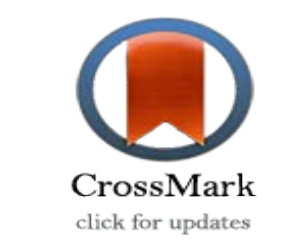

\title{
Comparison of the effect of sleep hygiene education with the cognitive and behavioral method on the quality of sleep in elderly
}

\author{
Torabi A ${ }^{1}$, *Ilali E.S ${ }^{2}$, Emadian S.O ${ }^{3}$, Mousavinasab N ${ }^{4}$
}

1- MSc Candidate in Geriatric Nursing, Student Research Committee, Mazandaran University of Medical Sciences, Sari, Iran.

2- Assistant Professor, Department of Gerontology Nursing, Faculty of Nursing and Midwifery, Mazandaran University of Medical Sciences, Sari, Iran (Corresponding Author)

Email: paradis2082000@yahoo.com

3- Assistant Professor, Department of Psychology, Faculty of Psychology, Islamic Azad University, Sari, Iran.

4- Associate Professor, Department of Biostatistics, Faculty of Health Science, Mazandaran University of Medical Sciences, Sari, Iran.

\section{Abstract}

Introduction: Being an elderly is associated with major changes in the quality and pattern of sleep. The aim of this study was to determine the effect of sleep hygiene education compared to cognitive- behavioral methodology on the quality of sleep in the elderly patients referred to daily care centers.

Method: This is a quasi-experimental research conducted on two-groups of 80 elderly people referring to day care centers in Sari city. In one group, sleep health education was conducted and in the other group, cognitive-behavioral methodology was held. Eighty eligible elders were assigned to two groups of sleep hygiene education $(40 \mathrm{~N})$ and cognitive-behavioral intervention $(40 \mathrm{~N})$. Sleep quality was assessed by Pittsburgh sleep quality standard questionnaire before and after intervention. At the beginning of the study, questionnaires (demographic characteristics questionnaire and Pittsburgh sleep quality questionnaire) were completed in both groups. Data was analyzed by SPSS v. 20 and descriptive and inferential statistics.

Results: The mean age of the samples was $66.15 \pm 4.22$ in the cognitive behavioral group and it was $67.95 \pm 5.53$ in the sleep hygiene education group. The mean and standard deviation of sleep quality of elderly people, before and after the cognitive behavioral method in the first group were $8.05 \pm 3.651,6.67 \pm 2.66$ respectively, the mean and standard deviation of sleep quality in the elderly before and after the sleep hygiene education in the second group were8.42 $\pm 3.39,7.23 \pm 2.454$ respectively. Comparison of the mean of sleep quality before and after intervention in both groups showed that the sleep quality of the elderly was significantly improved $(\mathrm{P}<0.001)$. Given that the $\mathrm{F}$ statistics of covariance analysis test is significant $(\mathrm{F}(1.79)=0.999, \mathrm{P}=$ 0.321 ), Therefore, these two methods had the same effect on the overall quality of sleep in the elderly

Conclusion: Considering that Cognitive- behavioral and sleep hygiene education method are an effective alternative to medication therapy replacement in the elderly, and each of the two methods have no side effects, it is recommended that, given the based on economic conditions and social facilities for the elderly, and facilities available to them. Each of these two alternatives is a substitute for hypnotics.

Keywords: Sleep quality, sleep hygiene, Cognitive-behavioral method, and elderly.

Received: 14 September 2019

Accepted: 3 November 2019 


\section{مقايسه تاثير آموزش بهداشت خواب باروش شناختى رفتارى بر كيفيت خواب سالمندان مراجعه كننده به مراكز مر اقبتى روزانه}

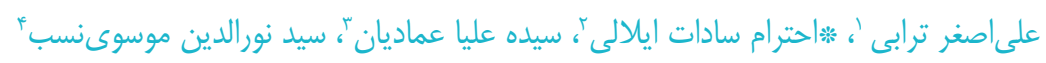

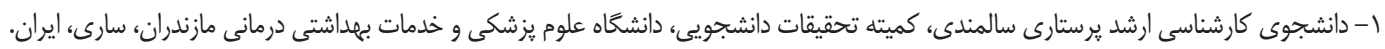

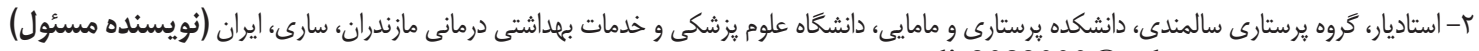

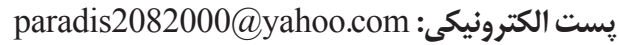

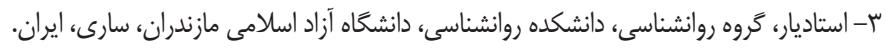

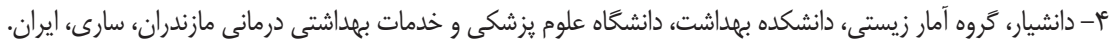

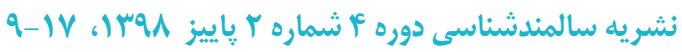

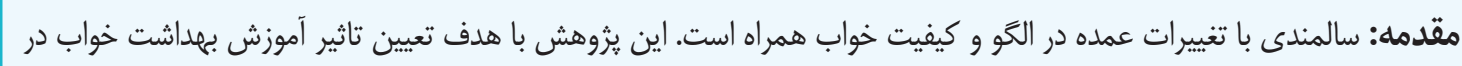

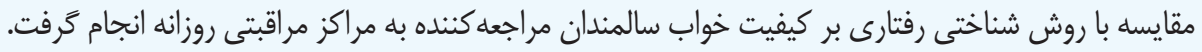

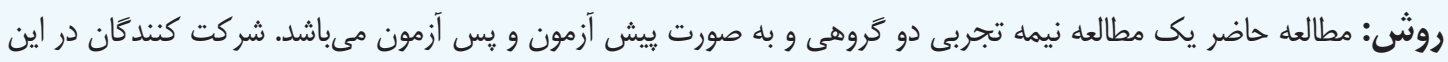

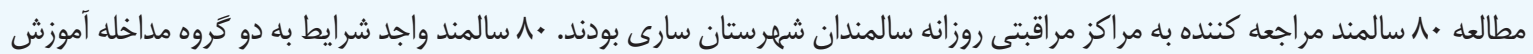

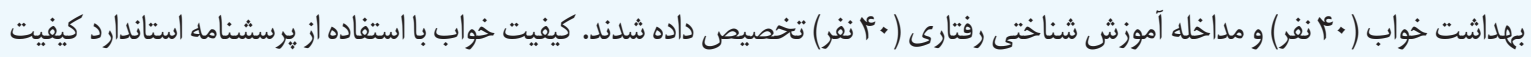

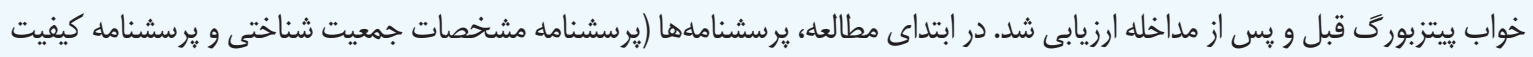

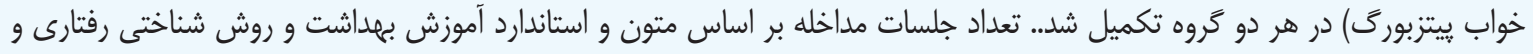

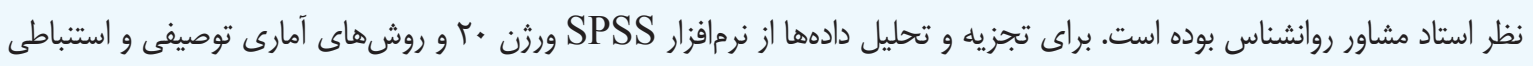
استفاده گرديد.

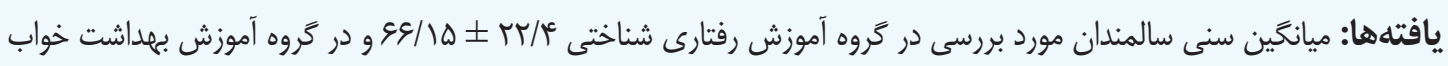

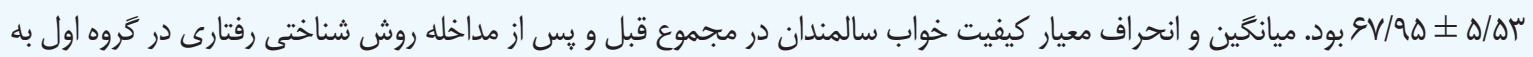

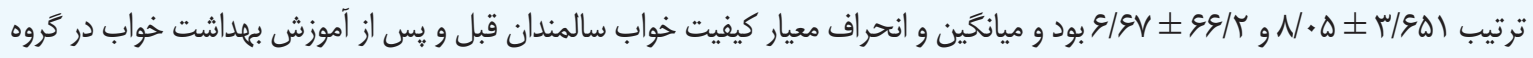

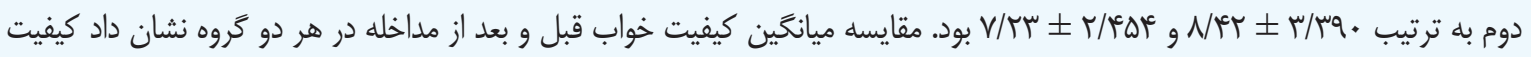

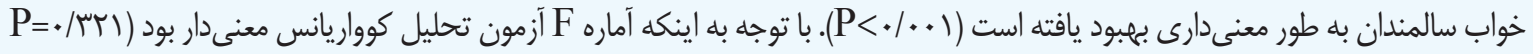

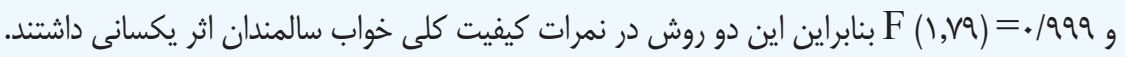

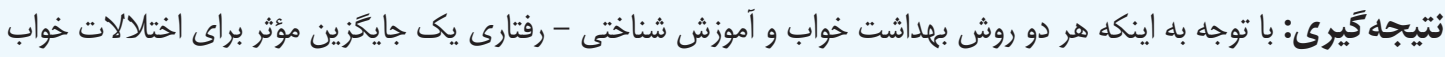

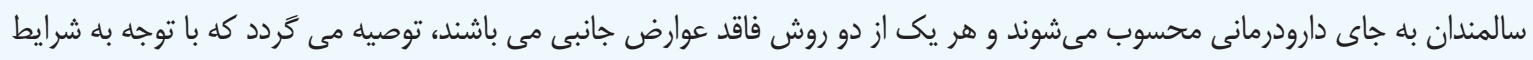

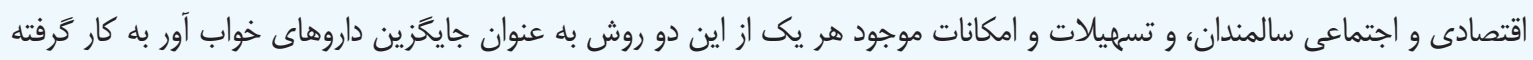

$$
\text { شوند. }
$$

رتبه سوم مشكلات سالمندان قرار دارد و يكى از مشكلات شايع و از هollo

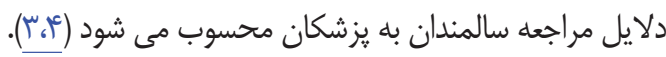

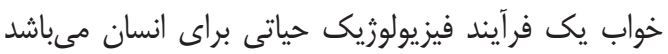
و يكى از عواملى است كه نقش مهمى در سلامت انسان دارد

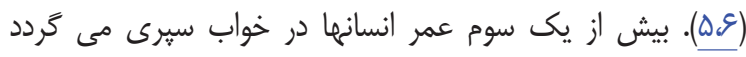

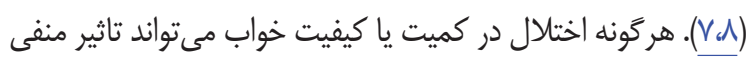

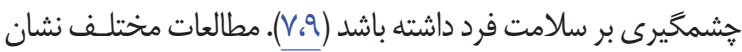

سالمندى با تغييرات عمده در الكو و كيفيت خواب همراه

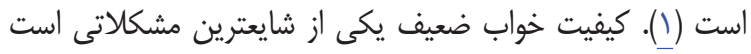

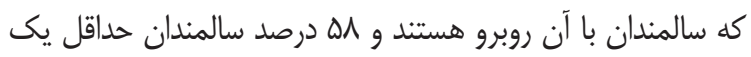
شب در هفته، بيخوابى را تجربه مى كنند (؟َ). تحقيقات نشان داده

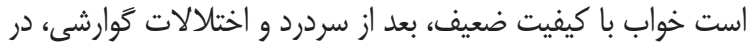


بود يزوهشكران بر آن شدند تا مطالعه حاضر را با هدف مقايسه تاثير

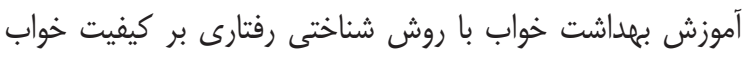
سالمندان مراجعل كننده به مراكز مراقبتى روزانه طراحى نمايند و تاثير روني اين دو روش را بر كيفيت خواب سالمندان بررسى نمايند.

\section{ورش مطالعه}

مطالعه حاضر يك مطالعه نيمه تجربى دو گروهى و به صورت ييش آزمون و پِ آزمون مىباشد. شركت كنندكان در اين مطالعه سالمندان مراجعه كننده به مراكز مراقبتى روزانه مهر و سراى ارشد إند

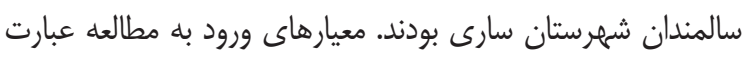

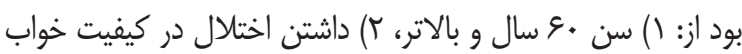
بر اساس يرسشنامه ييتزبورى (كسب نمره بالاتر از ه) ، ऍ) عدم ابتلا به اختلال سو مصرف مواد، أ) عضويت در مركز مراقبتى، ه) تمايل

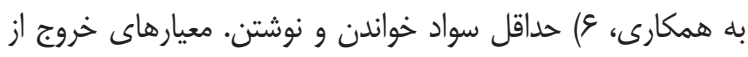

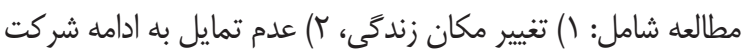

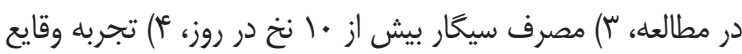
تنش زا در ع ماه اخير (فوت اقوام، سيل، تصادف، زلز له) براى مشاركت كنندكان و ها) فوت مشاركت كننده در طول انجام تحقيق. يُوهش

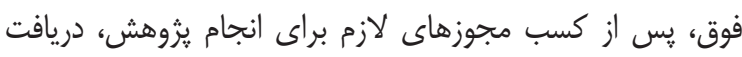

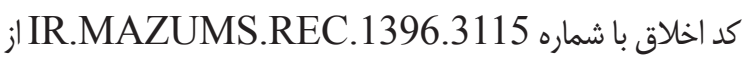
معاونت تحقيقات و فتاورى دانشخاه و يس از كسب رضايت نامه كتبى داري

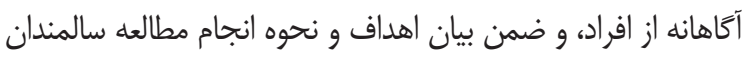

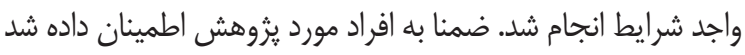
كه باسخهاى آنان در جهت اهداف يُوهش به به كار كرَفته خواهد شد. جهت جلوكيرى از تورش مخدوشگرى، با تخصيص تصادفى ساده،

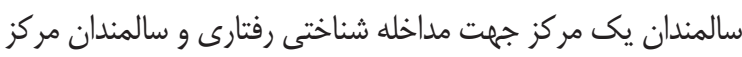

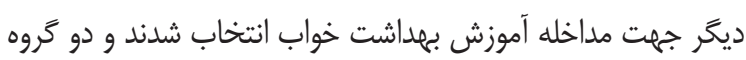

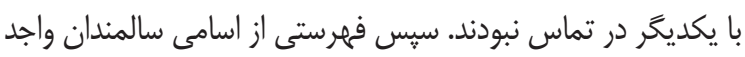

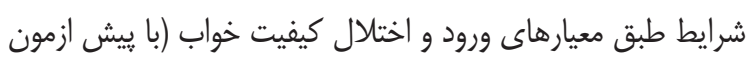
بر اساس يرسشنامه ييتزبورى و كسب نمره بيشتر از ه در آزمون)

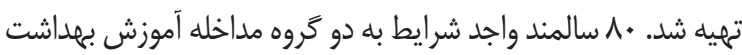

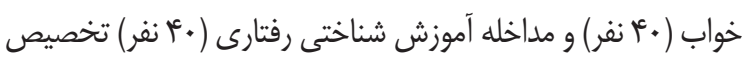

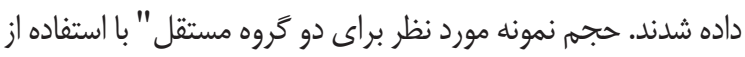
فرمول تعيين حجم نمونه در مطالعات مداخله اى و تفاضل ميانكَين

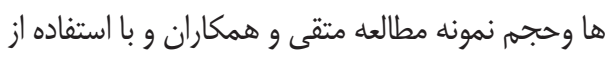
$01=02=4 / 5, \mu_{1}-\mu_{2=} 3$

با سطح اطمينان هو درصد و توان آزمون •^مدرصد، به تعداد

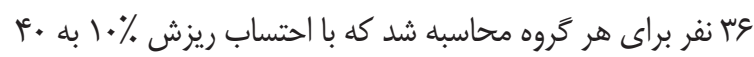

داده است كه كمبود خواب در ميان جمعيت سالمند با يِيامدهاى

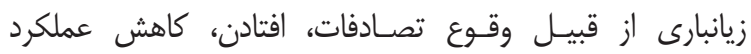

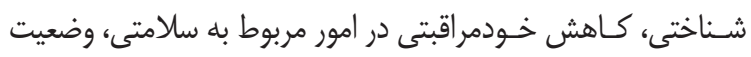

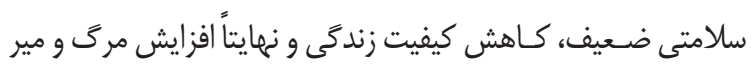

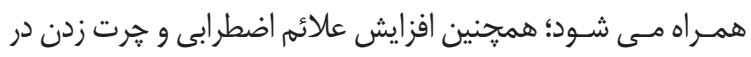

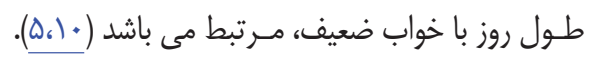

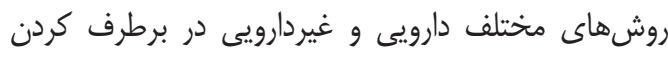

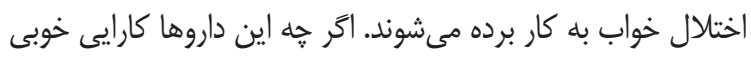
دارند ولى عوارض جانبى زيادى دارند كه به طور شايع در استفاده

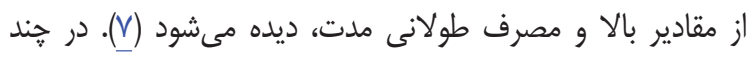

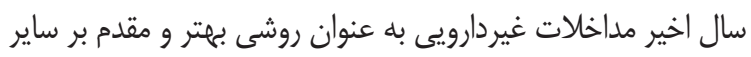
روشهاى موجود در بسيارى از مشكلات بيماران و همجنين در

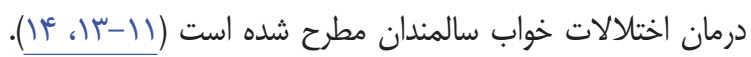

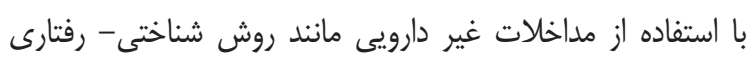

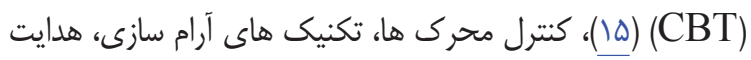

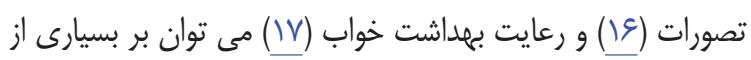

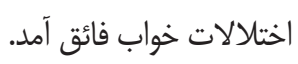
نتايج بعضى از مطالعات نشان داده است درمان شناختى -

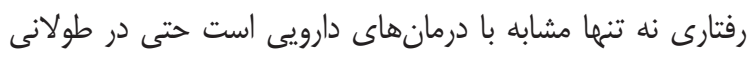

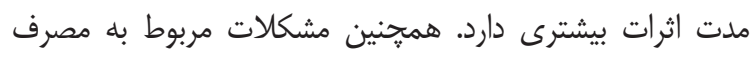

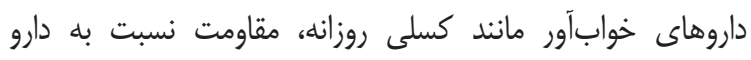

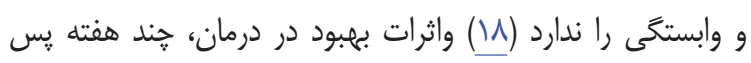

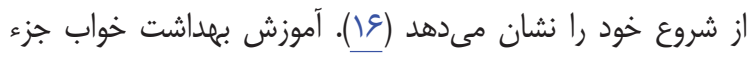
روش رفتاردرمانى است. هدف اصلى تكنيكهاى رفتارى كه در درمان

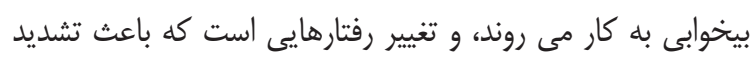

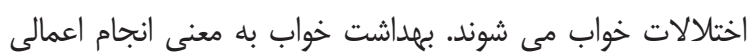
است در جهت حمايت از ريتهم طبيعى خواب و بيدارى و ارتقاى خواب

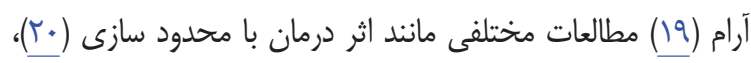

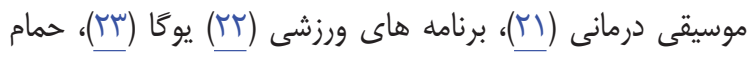

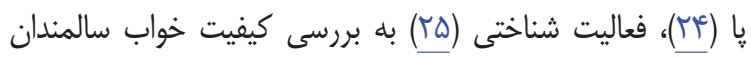

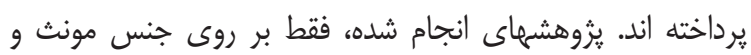

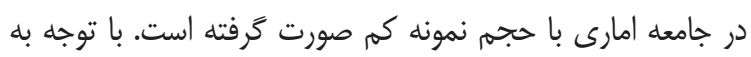

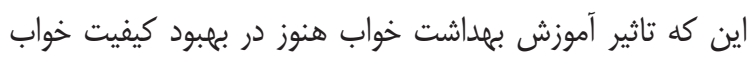

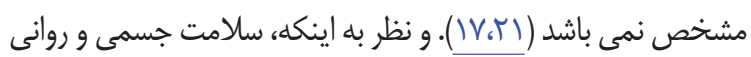
در دوران سالمندى نسبت به ساير دورههاى زندكى با خطر بيشترى

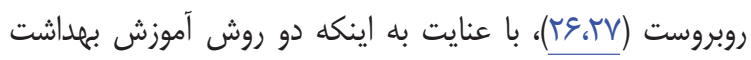

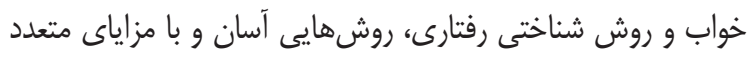
مىباشند، و تاكنون مقايسه اي هم بين اين دو روش صورت نحَّرفته 
و يرسشنامه كيفيت خواب ييتزبورى در هر دو گروه تكميل شد. يُوهشَّر پِ از آموزش مداخله شناختى رفتارى توسط اساتيد روانشناسى و اخذ تواهى مربوطه با همكارى روانشناس بالينى،

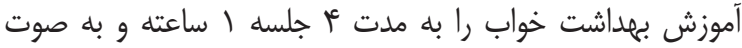

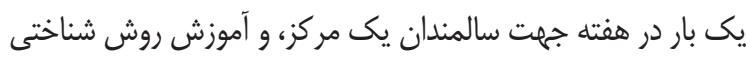

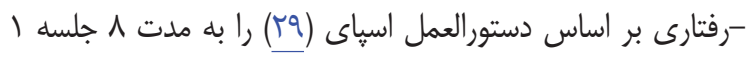
ساعته دو بار در هفته جهت سالمندان مركز ديخر اجرا نمود. تعداد

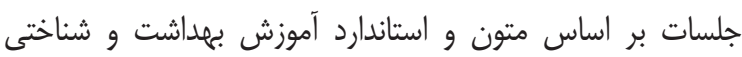
رفتارى و نظر استاد مشاور روانشناس بوده است. شرح جلسات آموزش بهداشت خواب بدين صورت بود: جلسه اول: آشنايى با اعضا، توافق اعضا در موردزمان و مكان آموزش، معرفى و بيان اهداف يزوهش، مفهوم و اهميت خواب، جلسه دوم: روشهاى بالى بررسى خواب و بررسى عوامل مؤثر بر خواب، جلسه سوم: آموزش دستورالعمل هاى كاهش عوامل مخرب خواب (محيط فيزيكى، رثيم

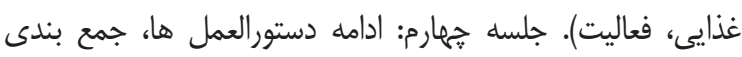

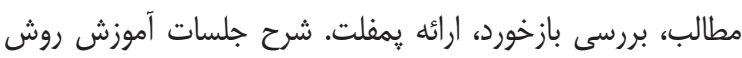
هاى شناختى رفتارى بر اساس دستورالعمل اسياى بدين صورت بود:

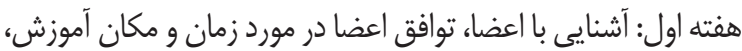
معرفى و بيان اهداف يزوهش، مفهوم و اهميت خواب، ارزيابى مشكل

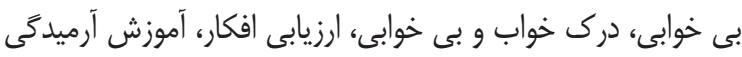
و تكاليف، هفته دوم: آرميدَى و زمان بندى جديد خواب، محدود سازى خواب، ممانعت از خرت زدن روزانه و انجام تكاليف، هفته سوم:

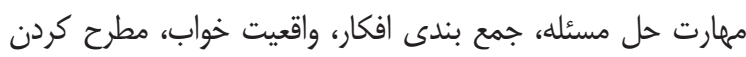

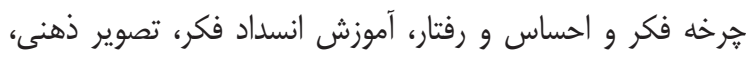

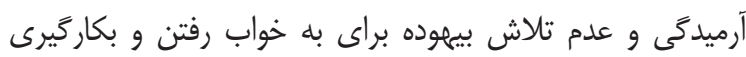

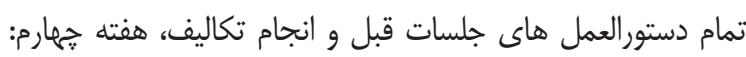
مطرح كردن كل طرح درمانى شناختى - رفتارى. در ابتداى هر جلسه مطالب جلسه قبل يرسيده شده و تكاليف مرتبط با جلسه قبل بررسى كَرديد. عدم حضور در دو جلسه به عنوان ريزش در نظر كرفته شد. بعد از بايان جلسات أموزشى، مجددا يرسشنامه كيفيت خواب دراب ي ييتزبورى توسط يزوهشكر تكميل شد. براى تجزيه و تحليل اطلاعات جمعآورى شده از برنامه

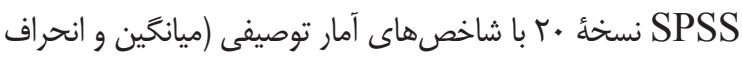

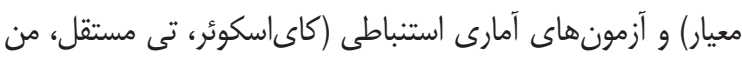

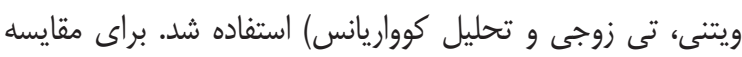

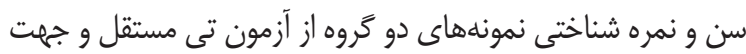

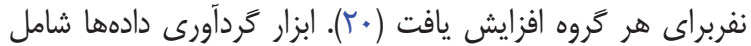
يرسشنامه مشخصات جمعيتشناختى (سن، جنس، سطح تحصيلات، درآمد ماهيانه، وضعيت تأهل، وجود يا عدم وجود بيمارى زمينهاى، استعمال سيكار، استعمال موادمخدر، مشكل بينايى، مشكل شنوايى و

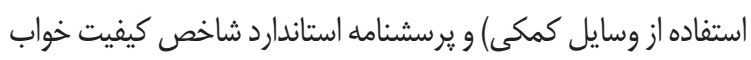
ييتزبورى بود. برسشنامه استاندارد شاخص كيفيت خواب يِيتزبورى

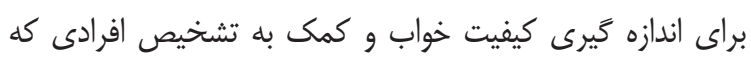
خواب خوب يا بد دارند، استفاده مى گردد. اين يرسشنامه در سال 1919 توسط بويس و همكاران در موسسه روانيزشكى بيتسبورى

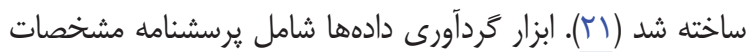
جمعيتشناختى (سن، جنس، سطح تحصيلات، حدود درآمد ماهيانه، وضعيت تأهل، وجود يا عدم وجود بيمارى زمينهاى، استعمال سيكار، استعمال مواد مخدر، مشكل بينايی، مشكل شنوايى و استفاده از

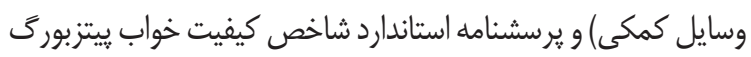
بود. يرسشنامه استاندارد شاخص كيفيت خواب ييتزبور كَ براى اندازه كيرى كيفيت خواب و كمك به تشخيص افرادى كه خواب خوب

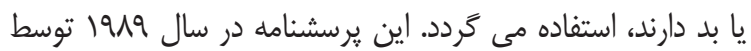
بويس و همكاران در موسسه روانيزشكى ييتسبورك ساخته شد (^؟) يرسشنامه داراى 9 ايتم است؛ اما جون سوال ه خود شامل • • آيتم فرعى است، كل يرسشنامه داراى 19 آيتم مى شود. اين يرسشنامه

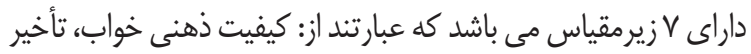
در به خواب رفتن، مدت زمان خواب، ميزان بازدهى خواب، اختالات خواب، استفاده از داروهاى خوابآور و اختالالات عملكردى روز روانها

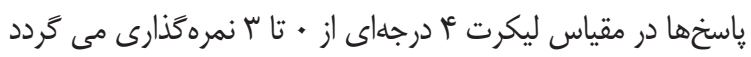

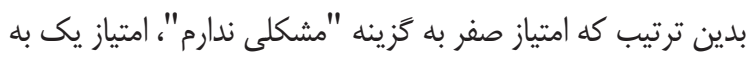

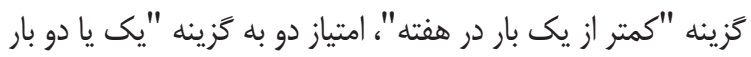

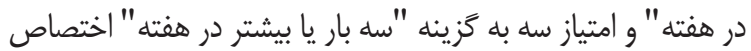
داده مىشود. نمره كل برسشنامه بين • تا ال در نظر كرفته شد. نمرهى ينج و بيشتر نشان مىدهد كه شخص مشكل خواب دارد، به عبارت ديخر نمره بإيين تر به منزله اختلال خواب كمتر و نمره

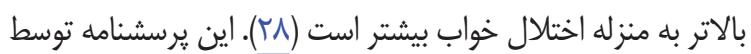

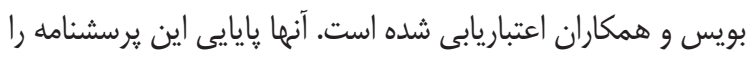

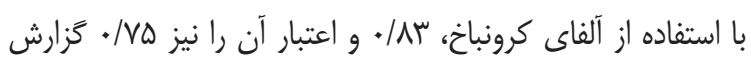

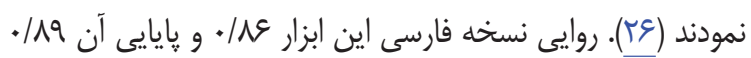
كزارش شده است (1)). در ابتداى مطالعه، يرسشنامه مشخصات جمعيت شناختى 


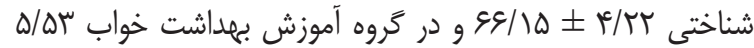

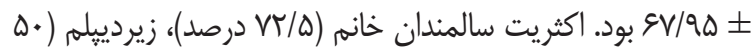
درصد) و بيوه و متاهل (T// د درصد) بودند. سطح درآمد اكثريت

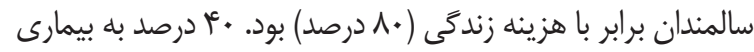
زمينه اى مبتلا بوده و س/ آ درصد سيعًارى بودند. (جدول ()).
مقايسه جنس، درآمد ماهيانه، وضعيت تأهل، وجود يا عدم وجود بيمارى زمينه ای، استعمال مواد مخدر، مشكل بينايى، مشكل شنوايى و استفاده از وسايل كمكى از آزمون آمارى كاى دو استفاده شد. ميانكَين سنى سالمندان مورد بررسى در گروه آموزش رفتارى

جدول (ا: ويزَگ هاى جمعيت شناختى - طبى و مقايسه همخنى در دو گروه مداخله در سالمندان مراكز مراقبتى روزانه

\begin{tabular}{|c|c|c|c|c|}
\hline سطح معنى دارى & $\begin{array}{c}\text { آموزش بهداشت خواب } \\
\text { Mean ISD }\end{array}$ & $\begin{array}{c}\text { آموزش شناختى رفتارى } \\
\text { Mean } \pm \text { SD }\end{array}$ & مشخصات & متغير \\
\hline $\begin{array}{l}.1817 \\
.1997 \\
.1999\end{array}$ & 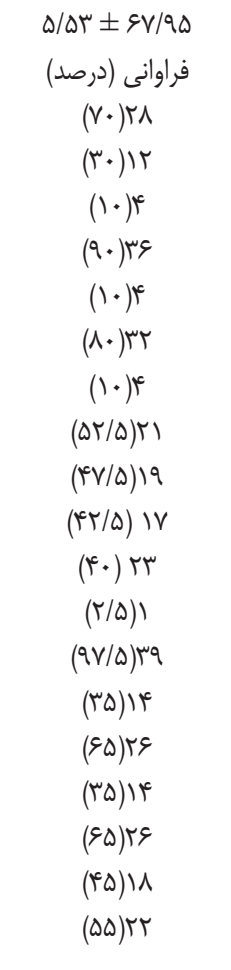 & 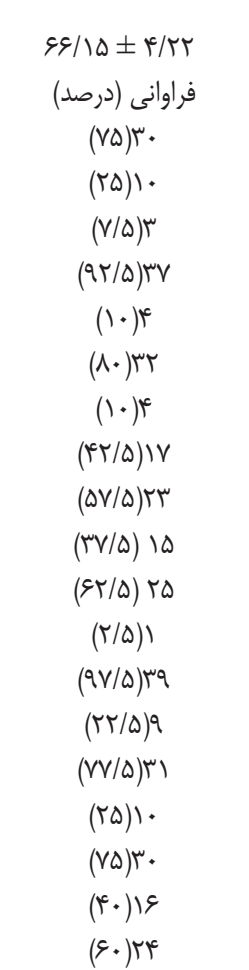 & 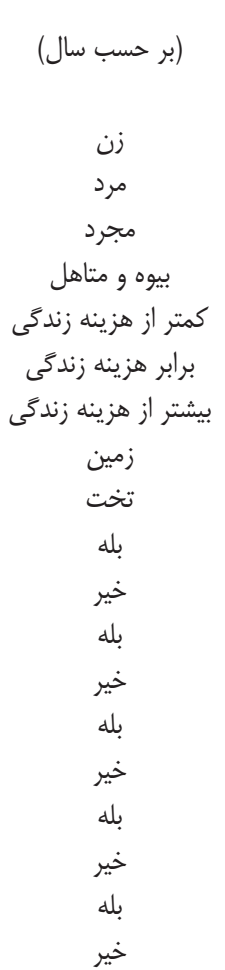 & 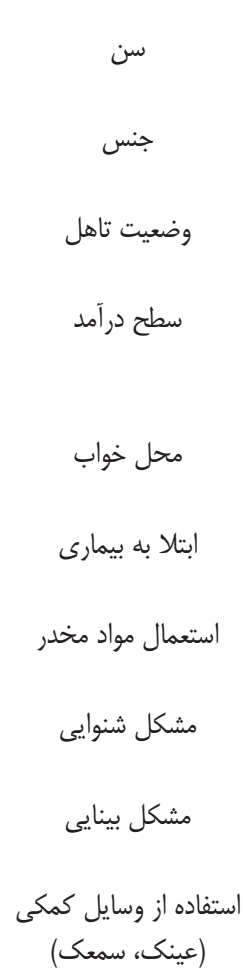 \\
\hline
\end{tabular}

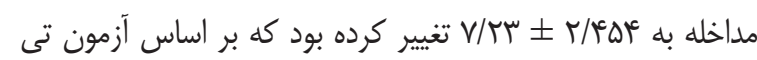

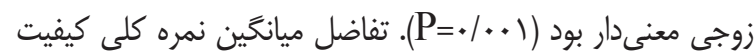
خواب قبل و بعد از مداخله در گروه هاى آموزش شناختى رفتارى و آموزش بهداشت خواب به ترتيب • •

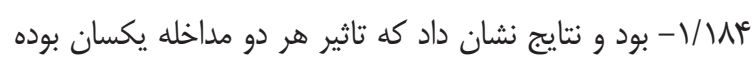

$$
\text { است (P=•/grV). }
$$

نتايج (جدول r)، نشان داد كه يس از حذف اثر يِيش آزمون به عنوان عامل مخدوشَّر اختلاف معنى دارى بين دو گروه (آموزش بهداشت خواب و روش شناختى -رفتارى) پِ از مداخله وجود نداشت

$$
(\mathrm{P}>\cdot / \cdot \Delta)
$$

ميانگين نمره كيفيت كلى خواب قبل از مداخله در دو گروه روش شناختى -رفتارى و آموزش بهداشت خواب به ترتيب الها؟

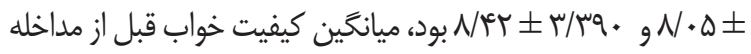

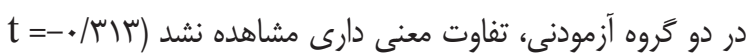
و P =^/VDD). نتايج مطالعه نشان داد، كه در اثر مداخله صورت گرفته در گروه تحت آموزش شناختى رفتارى، نمره كلى كيفيت خواب سالمندان، به طور متوسط از نمره اله/

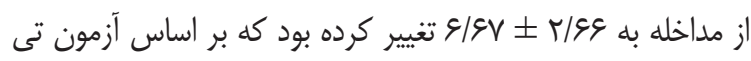

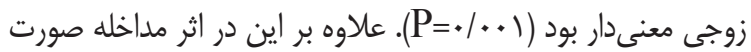
كَرفته در گروه تحت آموزش بهداشت خواب، نمره كلى كيفيت

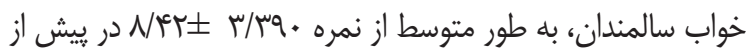


جدول ז: تحليل كوواريانس اثر روش شناختى درمانى درمانى و آموزش بهداشت خواب بر ميزان كيفيت خواب سالمندان در كل در هر دو كروه آزمودنى سالمندان مراجعه كننده به مراكز مراقبتى روزانه

\begin{tabular}{|c|c|c|c|c|c|c|}
\hline $\begin{array}{c}\text { Partial Eta } \\
\text { Squared }\end{array}$ & سطح معنى دارى & F آماره F & ميانكين مربعات & درجه آزادى & مجموع مربعات & منبع تغييرات \\
\hline $\begin{array}{l}. / 9 \mathrm{~V} . \\
. / .14\end{array}$ & $\begin{array}{l}.|.| 1 \\
. / 4 T \mid\end{array}$ & $\begin{array}{l}\mid 198 / \cdot 1 V \\
. / 999\end{array}$ & $\begin{array}{c}r r \cdot / v 9 \Delta \\
r / 9 Q \Delta \\
r / / q V\end{array}$ & $\begin{array}{c}1 \\
1 \\
v r\end{array}$ & $\begin{array}{l}r r . / V 9 D \\
r / 19 D \\
\text { IDN/IAT }\end{array}$ & بيش آزمون \\
\hline
\end{tabular}

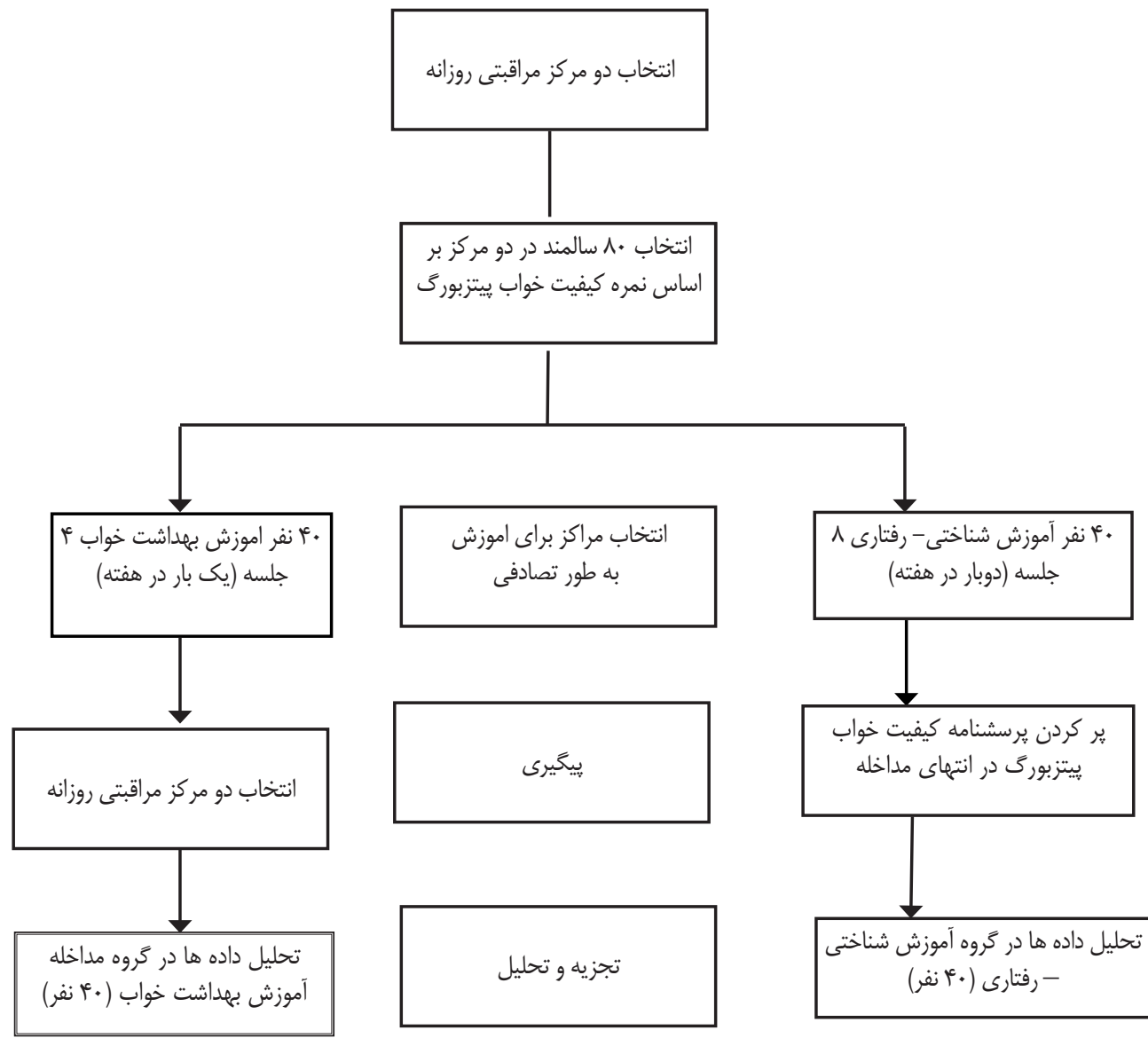

دياترام كونسورت

خواب سالمندان، نشان دادند كه درمان شناختى -رفتارى منجر به

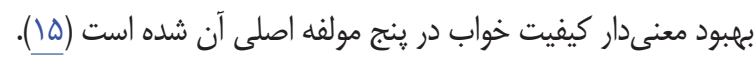
اين يزوهش با هدف مقايسه تاثير آموزش بهداشت خواب با

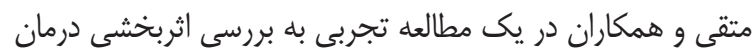

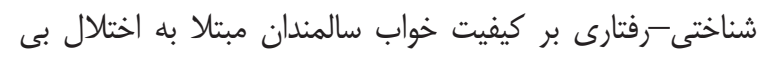

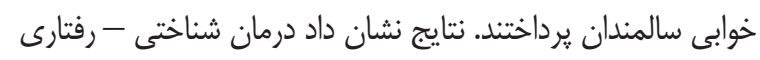

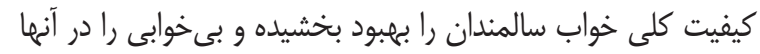

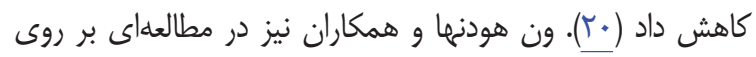

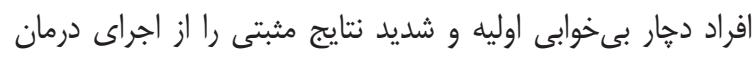

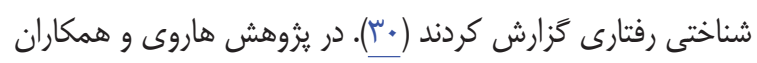
بيماران مبتلا به بى خوابى تحت يك دوره درمان شناختى - رفتارى

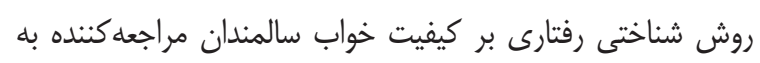

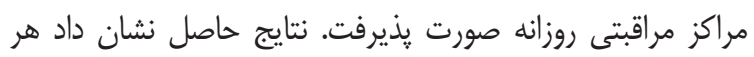

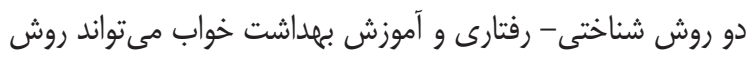

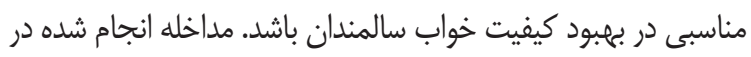

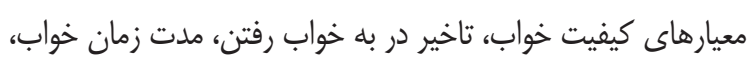

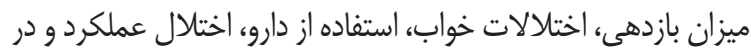

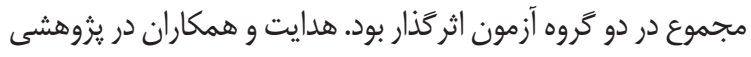
تجربى، با هدف بررسى تاثير درمان شناختى -رفتارى بر بهبود كيفيت 
مى بخشد. به نظر مى رسد رعايت اصول خواب خوب مى تواند از

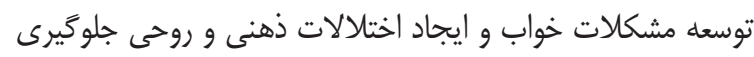

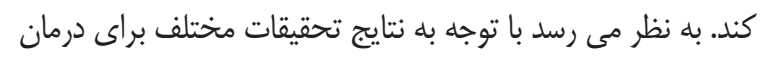
بى خوابى تغيير سبك زندگى و رعايت اصول بهداشت خواب بسيار كمك كننده است، بنابراين سالمندان مبتلا به كيفيت خواب ضعيف براى انجام رفتارهاى ارتقاء دهنده كيفيت خواب نيازمند توجه بيشتر

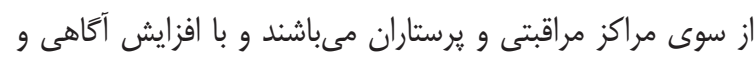

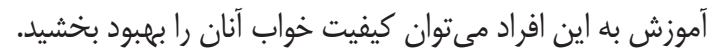

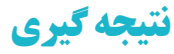

مداخله روش شناختى - رفتارى و آموزش بهداشت خواب تاثير معنى دار و مشابهى بر روى كيفيت خواب سالمندان داشت. هر دو روش در بهبود كيفيت كلى خواب به طور يكسان عمل كردند. در روش شناختى رفتارى، افكار و باورهاى ذهنى ناصحيح سالمند كه

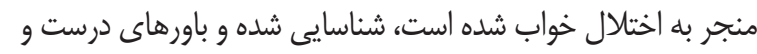
منطقى جايكز ين مى گردد؛ در نهايت اين روش منجر به كاهش فشار روانى و بهبود كاركردهايى مى شود كه در اثر ابتلا به اختالالهاى

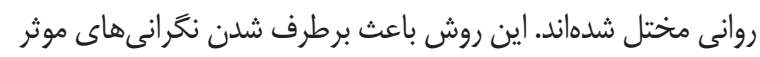

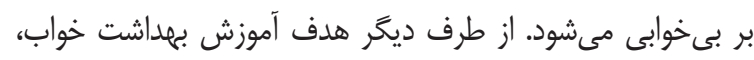

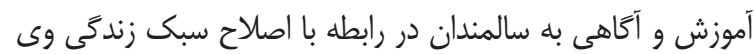
كه باعث آشفتحى در خواب شده است، مى باشد. علاوه بر اين هزينه

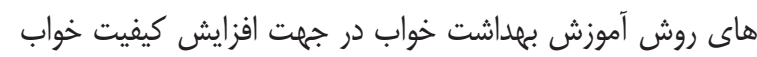
سالمندان كمتر از روش شناختى- رفتارى است و اين هزينه كمتر، به سود بيمار، خانواده او و در عين حال به سود سيستم مراقبت

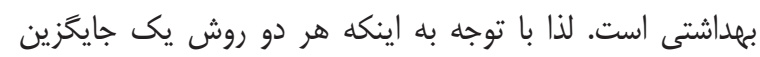

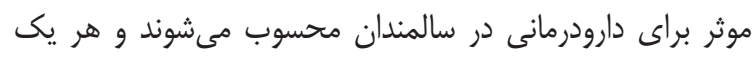
از دو روش شناختى- رفتارى و آموزش بهداشت خواب به عنوان دان ماندان

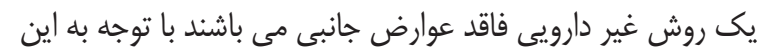

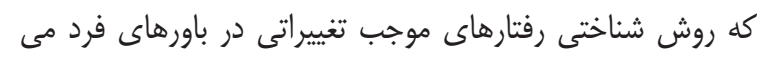

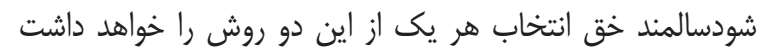

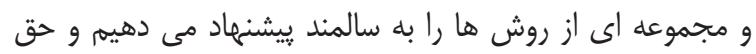

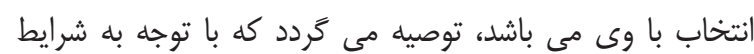

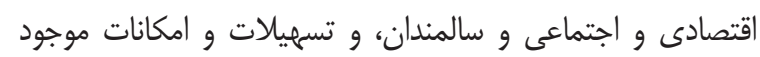
در اختيار آنها و ترجيحاتشان، هر يك از اين دو روش جايكزين

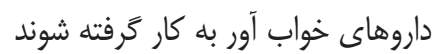

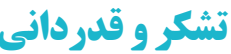

اين يزوهش با حمايت مالى دانشاه علوم يزشكى و خدمات
قرار كرفتند. نتايج بهبود معنادارى را در از بين بردن آشفتكى و علائم شبانه و روزانه بىخوابى و تغيير در شاخصهاى خواب اين بيماران

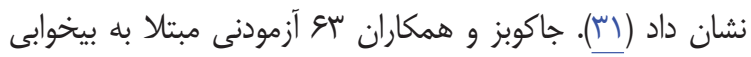
مزمن از نوع ناتوانى در شروع خواب را به سه كَروه درمانى شناختى رفتارى، دارو درمانى و كروه كنترل تقسيم كردند. نتايج نشان داد كه درمان شناختى رفتارى مداخله موثرترى براى بىخوابى است و منجر

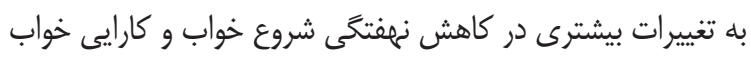

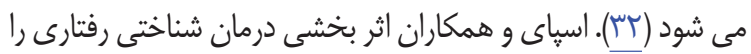
بر بىخوابى مزمن مورد يُوهش قرار دادند. نتايج نشان دهنده برترى درمان شناختى رفتارى بر خود سنجى در كاهش نهفتتى شروع برون

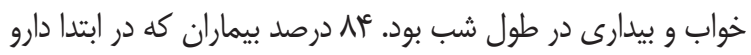
مصرف ميكردند در انتهاى درمان، دارو درمانى را قطع كردند (qج). نتايج تمامى تحقيقات ذكر شده اثربخشى روش شناختى رفتارى ران اندان

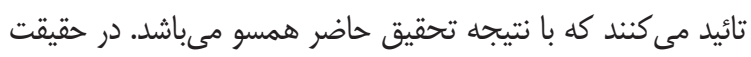
اساس درمان شناختى - رفتارى اين است كه نوع تفكر و الكوهاى فكرى و شناخت ما از محيط اطراف و خودمان و البته تفسير شخصى ما از اتفاقات زندگىى، باعث بروز رفتارها و احساسات ما مى شعود و به

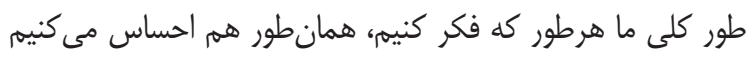
و رفتارهاى ما متناسب با همان افكار و احساسات شكل مى گيرند. بنابراين در اين روش درمانكر تلاش مى كند كه افكار غيرواقعى و

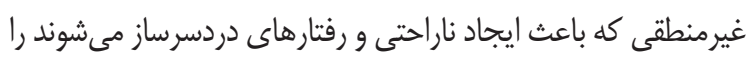

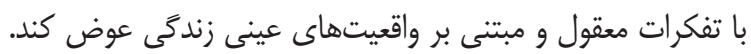
عالاه بر آن، اين روش درمانى شامل شناسايى دقيق مشكلات،

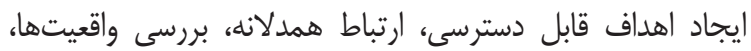

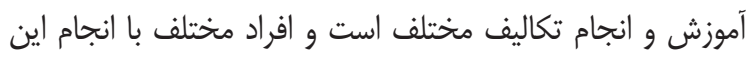
كارها مىتوانند تغييرات مثبت و سازندهاى در زندگى خود ايجاد كنند. طاهرى و همكاران به بررسى تاثير آموزش بهداشت خواب بر كيفيت خواب و سلامت عمومى زنان سالمند شهر بيرجند

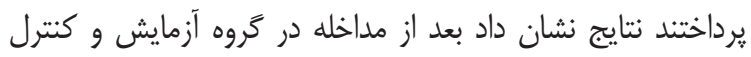

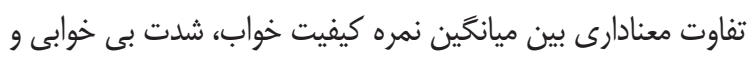
سلامت عمومى وجود داشت (سب).). در بروهش منتظرى و همكاران كه به بررسى تاثير آموزش بر عوامل مؤثر بر خواب زنان سالمند

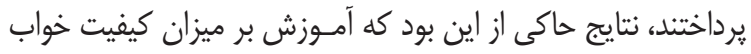
تاثير داشته است (عَب). نتايج مطالعه حاضر نيز اثر معنىدار آموزش بهداشت خواب بر كيفيت خواب سالمندان را تاكيد مى كند كه با نتايج

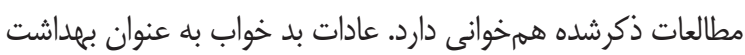

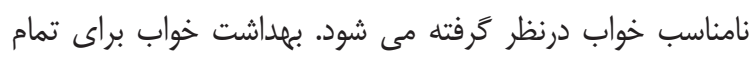

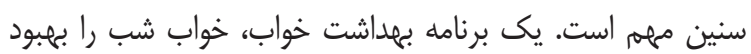




$$
\begin{aligned}
& \text { على اصغر ترابى و همكاران } \\
& \text { و قدردانى مى نمايند. نويسندكان اين مقاله لازم مىدانند مراتب }
\end{aligned}
$$

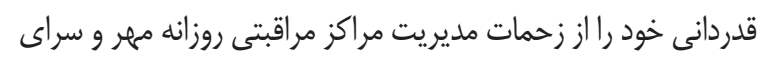

$$
\begin{aligned}
& \text { ارشد شهرستان سارى، يرسنل مراكز و تمامى سالمندان محترمى كه } \\
& \text { در اجراى اين يثوهش ما را يارى نمودند، ابراز نمايند. }
\end{aligned}
$$

\section{Refrences}

1. Campbell SS, Stanchina MD, Schlang JR, Murphy PJ. Effects of a Month-Long Napping Regimen in Older Individuals. Journal of the American Geriatrics Society. 2011; 59 (2): 22432.

2. Leger D, Poursain B, Neubauer D, Uchiyama M. An International Survey of Sleeping Problems in the General Population. Current Medical Research and Opinion. 2008; 24 (1): 307-17.

3. Richter K, Myllymaeki J, Scharold-Schaefer S, Tomova I, Mayrer R, Niklewski G. Treating Comorbid Insomnia in Older Adults via Cognitive-Behavioural Treatment, Bright Light and Exercise. Health. 2014; 6 (10): 960.

4. Rumble ME, Keefe FJ, Edinger JD, Porter LS, Garst JL. A Pilot Study Investigating the Utility of the Cognitive-Behavioral Model of Insomnia in Early-Stage Lung Cancer Patients. Journal of Pain and Symptom Management. 2005; 30 (2): $160-9$.

5. Valizadeh L, Seyyedrasooli A, Zamanazadeh V, Nasiri K. Comparing the Effects of Reflexology and Footbath on Sleep Quality in the Elderly: A Controlled Clinical Trial. Iranian Red Crescent Medical Journal. 2015; 17 (11). e20111

6. Farokhnezhad afshar $\mathrm{p}$, zahednezhad $\mathrm{h}$, ghanei gheshlagh r, fathi r. Effect of White Noise on the Sleep of Elderly Patients Hospitalized in Coronary Care Units. Iranian Journal of Ageing. 2016; 11 (1):44-51(Persian).

7. Zeighami $\mathrm{R}$, Jalilolghadr $\mathrm{S}$. Investigating the Effect of "Citrus Aurantium" Aroma on Sleep Quality of Patients Hospitalized in the Coronary Care Unit (CCU). Complementary Medicine Journal of faculty of Nursing \& Midwifery. 2014; 4 (1): 720 - 33 (Persian).

8. Moradi M, Mehrdad N, Nikpour S, Haghani H, Sharifi F. Sleep and Health Related Quality of Life in Patients with Chronic Heart Failure. Iranian Journal of Nursing Research 2013; 8 (29): 19-25 (Persian).

9. Jiro Imanishi EW, Satoko Watanabe, Kumi
بهداشتى درمانى مازندران انجام شده و طرح تحقيقاتى مصوب

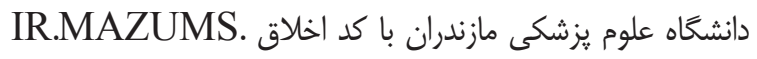

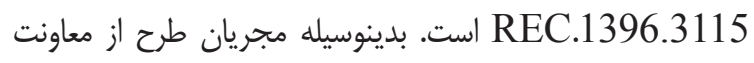

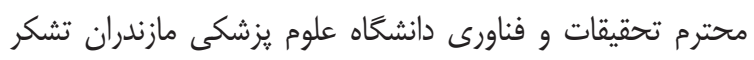

Sakurada, Zenshiro Onouchi. Improvement of Sleep and Circadian Rhythm Disturbance in Nursing Home Residents by Aromatherapy Massage: A Preliminary Study. JJCAM. 2010; 7 (2): 87-93.

10. Chan MF, Chan EA, Mok E. Effects of Music on Depression and Sleep Quality in Elderly People: a Randomised Controlled Trial. Complementary Therapies in Medicine. 2010; 18 (3-4): 150-9.

11. Doustian Y, Shafi'e-Abadi A, Kalantar-Koushe SM, Massah O. Effectiveness of Marlatt's Cognitive-Behavioral Model on Increasing Selfefficacy in Opiate-dependents. Rehabilitation Journal Addiction Special 2013; 14 (5): 91-9.

12. Izadi-Ajirlo A, Bahmani B, Ghanbari-Motlagh A. Effectiveness of Cognitive Behavioral Group Intervention on Body Image Improving and Increasing Self-Esteem in Women with Breast Cancer after Mastectomy. Rehabilitation Journal. 2012; 13 (4): 72-83.

13. .Nazer M, Riyahi N, Mokhtaree M. The Effect of Stress Management Training with Cognitive Behavioral Style on Stress and Mental Health of Parents of Children with Intellectual Disabilities Rehabilitation Journal. 2016; 17 (1): 32-41.

14. Kamrani AAA, Shams A, Abdoli B, Dehkordi PS, Mohajeri R. The Effect of Low and Moderate Intensity Aerobic Exercises on Sleep Quality in Older Adults. Sālmand. 2015; 10 (1): 72-81.

15. Hedayat S, Mokhtar A. The Effect of CognitiveBehavioral Therapy on Improving Sleep Quality in the Elderly. JSR. 2015; 16 (2): 60-8 (Persian).

16. Mottaghi R, Kamkar A, Maredpoor A. Effectiveness of Cognitive Behavior Therapy on the Quality of Sleep in Elderly People With Insomnia Disorder. Iranian Journal of Ageing. 2016;11 (2): 234 - 43 (Persian).

17. Hazeri A, Farahzadi H. Investigating the Efficacy of Sleep Hygiene Education on Improving Sleep Disorders in Shahid Sadoughi Hospital Nurses. Toloo-E-Behdasht. 2015; 14 (2 (50)): 47-56 (Persian).

18. Wang MY, Wang SY, Tsai PS. Cognitive 
Behavioural Therapy for Primary Insomnia: a Systematic Review. Journal of advanced nursing. 2005; 50 (5): 553 - 64.

19. Maris L,Mullan B.Self-monitoring vs, implementation intentions; A comparison of behaviour change techniques to improve sleep hygine and sleep outcomes in students. International journal of Behaviour Medicine.2015; 22 (5): 635 - 44.

20. Ahmadi S, Khankeh H, Mohammadi F, Khoshknab F, Reza Soltani P. The Effect of Sleep Restriction Treatment on Quality of Sleep in the Elders. Iranian Journal of Ageing. 2010; 5 (2): 0- (Persian).

21. Mottaghi R, Kamkar A, Mardpoor A. The Effectiveness of Targeted Music Therapy Intervention and Cognitive-Behavioral Therapy on Sleep Quality and Symptoms of Insomnia Disorder in seniors. The International Journal of Indian Psychology. 2015; 2 (4): 114 - 27.

22. Elavsky S, McAuley E. Lack of Perceived Sleep Improvement After 4-Month Structured Exercise Programs. Menopause. 2007; 14 (3): 535 - 40.

23. Hegde A, Metri K, Chwadhary P, Babu N, Nagendra H. Effects of Yoga on Cardiac Health Sleep Quality, Mental Health and Quality of Life of Elderly Individuals with Chronic Ailments: a Single Arm Pilot Study. 2017.

24. Seyyedrasooli A, Valizadeh L, Zamanzadeh V, Nasiri K, Kalantri H. The Effect of Footbath on Sleep Quality of the Elderly: a Blinded Randomized Clinical Trial. Journal of Caring Sciences. 2013; 2 (4): 305.

25. Pa J, Goodson W, Bloch A, King AC, Yaffe K, Barnes DE. Effect of Exercise and Cognitive Activity on Self-Reported Sleep Quality in Community-Dwelling Older Adults with Cognitive Complaints: a Randomized Controlled Trial. Journal of the American Geriatrics Society. 2014; 62 (12): 2319 - 26.

26. Momeni K, Karimi H. The Comparison of General Health of the Residents/Non Residents in the Elder House. Iranian Journal of Ageing. 2010; 5 (3): 0- (Persian).

27. Bahrami einolghaziH, khodabakhshi kolaii A, Taghvaii D. Efficacy of group physical activity on sleep quality and quality of life among older adults in Kahrizak nursing home. journal of gerentology. 2016; 1 (1): 30 - 8 .
28. Buysse DJ, Reynolds CF, Monk TH, Berman SR, Kupfer DJ. The Pittsburgh Sleep Quality Index: a New Instrument for Psychiatric Practice and Research. Psychiatry Research. 1989; 28 (2): $193-213$.

29. Espie CA. "Stepped Care": A Health Technology Solution for Delivering Cognitive Behavioral Therapy as a First Line Insomnia Treatment. Sleep. 2009; 32 (12): 1549 - 58.

30. Van Houdenhove L, Buyse B, Gabriëls L, Van den Bergh O. Treating Primary Insomnia: Clinical Effectiveness and Predictors of Outcomes on Sleep, Daytime Function and Health-Related Quality of Life. Journal of Clinical Psychology in Medical Settings. 2011; 18 (3): 312 - 21.

31. Harvey AG, Sharpley AL, Ree MJ, Stinson K, Clark DM. An Open Trial of Cognitive Therapy for Chronic Insomnia. Behaviour Research and Therapy. 2007; 45 (10): 2491 - 501.

32. Jacobs GD, Pace-Schott EF, Stickgold R, Otto MW. Cognitive Behavior Therapy and Pharmacotherapy for Insomnia: A Randomized Controlled Trial and Direct Comparison. Archives of Internal Medicine. 2004; 164 (17): 1888 - 96.

33. Taheri Tanjani P, Khodabakhshi H, Etemad K, Mohammadi M.Effect of Sleep Hygiene Education on Sleep Quality and General Health of Elderly Women With Sleep Disorders Living in Birjand City, Iran,in 2016. Iranian Journal of Ageing. 2019; 14 (2): 248 - 59

34. Montazeri Lemrasky M, Shamsalinia A, Haji Ahmadi M, Nasiri M. The Effectiveness of Education on Factors Affecting Elderly Women's Sleep. Journal of Caspian Health and Aging. 2018; 3 (1): 59 - 68. 